\title{
O tratamento térmico influencia as características físico-químicas e oxidativas do óleo de coco
}

\section{The heat treatment influences the physico-chemical and oxidative characteristics of coconut oil}

\author{
Bruna Cristina dos Santos Cruz ${ }^{1}$, Camila Gonçalves Oliveira Chagas², Ana Vládia Bandeira \\ Moreira $^{3}$
}

\section{Resumo}

O objetivo deste estudo foi avaliar o efeito do tratamento térmico sobre o perfil de ácidos graxos, capacidade antioxidante, oxidação lipídica e características físico-químicas do óleo de coco. As análises foram realizadas com amostras do óleo de coco in natura, aquecido até o ponto de fumaça e utilizado na fritura de batatas. Foi avaliado o perfil de ácidos graxos, os índices de peróxidos e acidez, a formação de malondialdeído e a capacidade antioxidante do óleo de coco nas três condições. O perfil de ácidos graxos não diferiu nas distintas condições de análise; contudo, pode-se observar que o índice de acidez foi significativamente maior no óleo aquecido e utilizado na fritura. Para o índice de peróxidos, esse aumento ocorreu apenas no óleo aquecido. A formação de malondialdeído foi observada em todas as amostras, sendo maior no óleo aquecido, seguido do usado na fritura. A capacidade antioxidante foi menor nas amostras submetidas ao calor (diferença significativa). Conclui-se que os tratamentos térmicos aos quais o óleo de coco foi submetido, foram capazes de alterar suas características físicoquímicas e oxidativas. Considerando os possíveis malefícios associados ao consumo de óleos e gorduras degradados, desencorajamos a utilização do óleo de coco submetido a temperaturas elevadas. Enfatizamos a importância da criação de metodologias específicas para avaliação da qualidade de óleos e gorduras submetidas ao aquecimento, por possibilitar um melhor controle dos aspectos nutricionais e sensoriais dos óleos/gorduras destinados ao consumo.

Palavras chave: Óleo de coco. Estresse oxidativo. Perfil lipídico.

\begin{abstract}
The objective of this study was to evaluate the effect of heat treatment on the profile of fatty acids, antioxidant capacity, lipid oxidation and physical-chemical characteristics of coconut oil. The analyzes were carried out with samples of the coconut oil in natura, heated to the "point of smoke" and used to fry the potatoes. The fatty acid profile, the peroxide and acidity indexes, the malondialdehyde formation and the antioxidant capacity of the coconut oil were evaluated in three conditions. The fatty acid profile did not differ in the different conditions of analysis; however, it may be observed that the acid value was significantly higher in the heated oil and used in frying. For the peroxide index, this increase occurred only in the heated oil. The formation of malondialdehyde was observed in all the samples, being higher in the heated oil, followed by the one used in the frying process. The antioxidant capacity was significantly lower in the heated samples. It concluded that the thermal treatments to which the coconut oil was subjected, were able to modify its physicochemical and oxidative characteristics. Considering the possible damages associated with the oils and degraded fats consumption, we discourage the use of coconut oil subjected to high temperatures. We emphasize the importance of the creation of specific methodologies for quality evaluation of oils and fats submitted to the heating, which allows a better control of nutritional and sensorial aspects of the oils destined for consumption.
\end{abstract}

Keywords: Coconut oil. Oxidative stress. Lipid profile.

\footnotetext{
${ }^{1}$ Mestranda em Ciência da Nutrição pela Universidade Federal de Viçosa, Viçosa, Minas Gerais, Brasil. E-mail: brunacruz09@yahoo.com.br ${ }^{2}$ Mestre em Ciência da Nutrição, Universidade Federal de Viçosa, Viçosa, Minas Gerais, Brasil.

${ }^{3}$ Doutora em Ciência dos Alimentos pela Universidade de São Paulo, São Paulo, Brasil. Docente do Departamento de Nutrição da Universidade Federal de Juiz de Fora, Juiz de Fora, Minas Gerais, Brasil.
} 


\section{Introdução}

O papel que os componentes da dieta exercem na prevenção e no desenvolvimento de agravos à saúde, assim como seus mecanismos de ação, têm sido objetos de estudos há décadas. Os lipídeos ganharam destaque nesse contexto, sendo associados ora à gênese de doenças crônicas, ora à modulação da inflamação sistêmica, perda de peso e melhora do desempenho físico. ${ }^{(1)}$ Os desfechos irão depender da qualidade e quantidade dos lipídeos ingeridos, mais especificamente, dos ácidos graxos que os compõem. ${ }^{(2)}$

O óleo de coco é caracterizado pela predominância de ácidos graxos saturados, sendo o ácido graxo láurico (C12:0) o mais representativo (cerca de $50 \%$ ); ${ }^{(3)}$ os triglicerídeos de cadeia média (TCM) correspondem a cerca de $70 \%$ a $80 \%$ do total. ${ }^{(4)}$ A presença dos TCM confere ao óleo de coco um comportamento metabólico diferente das demais gorduras saturadas e, por isso, é sugerido que seu consumo seja menos deletério quando comparado à gordura saturada de origem animal, rica nos ácidos graxos mirístico (C14:0) e palmítico (C16:0) que são ácidos graxos de cadeia longa. ${ }^{(5)}$

Contudo, sabe-se que o destino metabólico dos ácidos graxos produzidos pelo organismo ou ingeridos através da dieta, depende de fatores relacionados à sua estrutura, especificidade enzimática e componentes dietéticos capazes de influenciar seu metabolismo. (6) O resultado será determinante para a entrada do ácido graxo em uma via metabólica ou outra, como a $\beta$-oxidação ou lipogênese. ${ }^{(7)}$

O óleo de coco tem sido indicado para tratamento da obesidade, seja em sua forma in natura, em cápsulas ou no preparo dos alimentos, sendo recomendado como alimento seguro para o consumo, inclusive para ser utilizado nos processos de fritura por imersão. ${ }^{(8)}$ No entanto, a literatura é escassa no que diz respeito às alterações que o óleo de coco apresenta após ser submetido ao aquecimento.

Os óleos e gorduras quando aquecidos têm sua composição física, química e nutricional alterados, principalmente se o aquecimento ocorrer por períodos prolongados e sob altas temperaturas. ${ }^{(9)}$ Durante esse processo ocorrem reações químicas que envolvem: hidrólise, oxidação e polimerização da molécula do triacilglicerol e, ainda, trocas entre o alimento e o óleo/gordura. ${ }^{(10)}$ São formados produtos tóxicos, como a acroleína e os peróxidos. As alterações físicas e químicas resultam na produção de radicais livres, ácidos graxos trans, aldeídos (como o malondialdeído) e cetonas que, quando incorporados nos alimentos, podem causar doenças cardiovasculares, câncer, artrite e envelhecimento precoce. ${ }^{(11)}$

A estabilidade oxidativa é um importante parâmetro para avaliar a qualidade de óleos e gorduras, sendo que os compostos antioxidantes presentes nos óleos vegetais são, em parte, os responsáveis por essa propriedade. $^{(12)} \mathrm{O}$ óleo de coco possui compostos fenólicos (ácido ferúlico e ácido 4-hidroxibenzoico) que são capazes de prevenir ou inibir a cadeia oxidativa e, consequentemente, a peroxidação lipídica. ${ }^{(13)}$

Nesse sentido, entender as mudanças que os óleos e gorduras sofrem durante o aquecimento é fundamental. Diante da escassez de estudos que demonstram as alterações no óleo de coco submetido ao processo de cocção, o objetivo deste estudo foi avaliar o efeito do tratamento térmico sobre o perfil de ácidos graxos, capacidade antioxidante, oxidação lipídica e características físico-químicas do óleo de coco.

\section{Material e Método}

\section{Preparo das amostras}

Foi utilizado óleo de coco virgem orgânico, prensado a frio, adquirido por doação do fabricante (Dr. Orgânico ${ }^{\circledR}$ ). As análises do óleo foram realizadas em três condições diferentes: óleo de coco in natura (OCIN); óleo de coco usado em fritura de batata inglesa (OCFR) a $180^{\circ} \mathrm{C}$ e óleo de coco aquecido até obtenção do ponto de fumaça (OCAQ), que ocorreu a $190^{\circ} \mathrm{C}$ após 1 minuto de aquecimento. As análises foram realizadas em triplicatas.

\section{Determinação do perfil de ácidos graxos do óleo de coco}

O perfil de ácidos graxos foi determinado após esterificação das amostras, segundo protocolo proposto por Hartman e Lago. ${ }^{(14)}$ A identificação dos ésteres metílicos foi realizada por cromatografia gasosa, nas seguintes condições de experimentação: cromatógrafo a gás (Shimadzu $\left.{ }^{\circledR}\right)$ com detector de ionização de chama (FID - Flame Ionization Detector) equipado com coluna capilar de sílica fundida (100 $\mathrm{m} \times 0,25 \mathrm{~mm}$ ). A programação da temperatura foi de $80^{\circ} \mathrm{C}$, com rampa de aquecimento de $10^{\circ} \mathrm{C}$ por minuto até alcançar $150^{\circ} \mathrm{C} \mathrm{e} 4^{\circ} \mathrm{C} / \mathrm{min}$ até atingir a temperatura de $250^{\circ} \mathrm{C}$; temperatura do injetor mantida a $240^{\circ} \mathrm{C}$ e detector a $260^{\circ} \mathrm{C}$; gás de arraste hidrogênio ultrapuro, razão split:5 e fluxo da coluna de $1,6 \mathrm{~mL} / \mathrm{min}$. 
A identificação dos ácidos graxos foi realizada por comparação entre os tempos de retenção das amostras e dos padrões de ésteres metílicos.

\section{Determinação do índice de acidez}

Para determinação do índice de acidez, foram pesados $2 \mathrm{~g}$ de amostra e adicionado $25 \mathrm{~mL}$ de solução de éter-álcool (2:1) e duas gotas do indicador fenolftaleína. A titulação foi feita com hidróxido de sódio $0,01 \mathrm{M}$ até o aparecimento da coloração rósea, persistindo por 30 segundos. ${ }^{(15)}$ Para o cálculo do índice de acidez, foi utilizada a fórmula: $\mathrm{V} \times \mathrm{F} \times$ $5,61 / \mathrm{p}$ (onde $\mathrm{V}=$ solução de hidróxido de sódio $0,01 \mathrm{M}$ gasto na titulação; $\mathrm{F}=$ fator de solução de hidróxido de sódio; $\mathrm{p}=$ peso em $\mathrm{g}$ da amostra). $\mathrm{O}$ resultado foi expresso em \% de ácido oléico $(\mathrm{m} / \mathrm{m})$.

\section{Determinação do índice de peróxidos}

O índice de peróxidos foi determinado por meio da capacidade da amostra em oxidar iodeto de potássio (KI). ${ }^{(15)}$ Para análise, foram pesadas $5 \mathrm{~g}$ de cada amostra, adicionado $30 \mathrm{~mL}$ da solução ácido acéticoclorofórmio (3:2), seguido de agitação até dissolução da amostra. Foi adicionado $0,5 \mathrm{~mL}$ da solução saturada de KI e as amostras ficaram em repouso ao abrigo de luz por 1 minuto. Acrescentou-se $30 \mathrm{~mL}$ de água e titulouse com solução de tiossulfato de sódio $\left(\mathrm{Na}_{2} \mathrm{~S}_{2} \mathrm{O}_{3}\right) 0,1$ N. A titulação foi continuada com solução de amido indicadora, até o completo desaparecimento da coloração azul. O branco foi preparado nas mesmas condições. ${ }^{(15)}$ Para o cálculo do índice de peróxido, foi utilizada a fórmula: (A-B) x N x F x 1000/p (onde A = volume de sol $_{u} c_{\mathfrak{a}}$ o de $\mathrm{Na} 2 \mathrm{~S} 2 \mathrm{O} 3 \mathrm{~N}, 1 \mathrm{~N}$ gasto na titulação da amostra; $\mathrm{B}=\operatorname{vol}_{\mathrm{u}} \mathrm{m}_{\mathrm{e} d}$ e solução de $\mathrm{Na} 2 \mathrm{~S} 2 \mathrm{O} 30,1$ $\mathrm{N}$ gasto na titulação do branco; $\mathrm{N}=$ normalidade da solução de $\mathrm{Na}_{2} \mathrm{~S}_{2} \mathrm{O}_{3} ; \mathrm{F}$ = fator da solução de $\mathrm{Na}_{2} \mathrm{~S}_{2} \mathrm{O}_{3}$; $\mathrm{p}=$ peso em $\mathrm{g}$ da amostra). Os resultados foram expressos em miliequivalentes $(\mathrm{mEq})$ por $1000 \mathrm{~g}$ da amostra.

\section{Teste do ácido 2-tiobarbitúrico}

O teste do ácido 2-tiobarbitúrico (TBA) consiste na reação deste com os produtos de decomposição dos hidroperóxidos. Neste ensaio, uma molécula de malondialdeído (MDA) reage com duas moléculas de TBA para formar um composto de cor vermelha, o qual absorve a $532-535 \mathrm{~nm}$. A reação ocorre em meio ácido $(\mathrm{pH} \mathrm{1-2})$ e em alta temperatura $\left(100^{\circ} \mathrm{C}\right)$, no sentido de aumentar sua velocidade e sensibilidade. O reagente de TBA é composto por $0,375 \%$ de TBA, $15 \%$ de ácido tricloroacético e $0,25 \%$ de $\mathrm{HCl}^{(16)}$

\section{Avaliação da atividade antioxidante}

A análise da atividade antioxidante foi realizada utilizando-se o percentual de sequestro do radical 2,2-difenil-1-picril-hidrazil (DPPH), conforme sugerido por Brand-Williams, Cuvelier e Berset. (17) Este método baseia-se na captura do radical DPPH pelos antioxidantes presentes nas amostras, produzindo um decréscimo da absorbância, medida por espectrofotometria a $517 \mathrm{~nm}$.

Foi utilizado o volume de $100 \mu \mathrm{L}$ de cada uma das amostras e adicionado $1,5 \mathrm{~mL}$ da solução DPPH. Os tubos foram agitados em vórtex por aproximadamente 1 minuto e, em seguida, foram mantidos em repouso por 30 minutos em ambiente protegido da luz. A absorbância foi determinada em espectrofotômetro modelo UV-1601® (Shimadzu Corporation, São Paulo, Brasil). As amostras foram analisadas em triplicata. A atividade de sequestro do radical (\%ARR) foi calculada utilizando a equação: $1-\left(\mathrm{A}_{\text {amostra }} / \mathrm{A}_{\text {controle }}\right)$ $\mathrm{x} 100$, onde $\mathrm{A}=$ absorbância. Os resultados foram expressos em percentual de redução da atividade do radical $\mathrm{DPPH}$.

\section{Análise estatística}

Os dados foram analisados no programa estatístico Statistical Package for the Social Sciences versão 20.0 (SPSS, Inc., Chicago, IL, USA) e os resultados descritos em média \pm desvio-padrão. As médias obtidas em cada condição de análise foram comparadas por Análise de Variância (ANOVA), seguido do teste post hoc de Tukey, quando apropriado. Para significância estatística, foi adotado o $\alpha \leq 0,05$.

\section{Resultados}

O perfil de ácidos graxos do óleo de coco mantevese inalterado sob as três condições de análise (Tabela 1). Foram identificados oito ácidos graxos nas amostras e a maioria deles atenderam aos valores preconizado pela RDC $n^{\circ} 482$ da Agência Nacional de Vigilância Sanitária. ${ }^{(4)}$ Apenas o ácido caprílico e o ácido linoléico, apresentaram percentuais diferentes do definido por essa Resolução. 
Tabela 1 - Perfil de ácidos graxos do óleo de coco in natura (OCIN), aquecido até o ponto de fumaça (OCAQ) e usado em fritura (OCFR)

\begin{tabular}{|c|c|c|c|c|c|}
\hline \multirow[b]{2}{*}{$\begin{array}{l}\text { Ácido } \\
\text { Graxo }\end{array}$} & \multirow[b]{2}{*}{ Nomenclatura } & \multicolumn{3}{|c|}{$\begin{array}{c}\text { Percentual de ácidos } \\
\text { graxos no óleo de } \\
\text { coco* }^{*}\end{array}$} & \multirow{2}{*}{$\begin{array}{l}\text { Referência } \\
\text { RDC n }{ }^{\circ} 482 \\
\quad(1999)\end{array}$} \\
\hline & & OCIN & OCAQ & OCFR & \\
\hline C8:0 & Caprílico & $\begin{array}{l}3,74^{\mathrm{a}} \\
\pm \\
0,94\end{array}$ & $\begin{array}{l}4,41^{\mathrm{a}} \\
\quad \pm \\
1,54\end{array}$ & $\begin{array}{l}4,45^{\mathrm{a}} \\
\pm \\
1,18\end{array}$ & $\begin{array}{l}5,0- \\
10,0\end{array}$ \\
\hline C10:0 & Cáprico & $\begin{array}{l}4,83^{\mathrm{a}} \\
\pm \\
0,70\end{array}$ & $\begin{array}{l}4,93^{\mathrm{a}} \\
\pm \\
0,92\end{array}$ & $\begin{array}{l}4,93^{\mathrm{a}} \\
\pm \\
0,86\end{array}$ & $\begin{array}{c}4,5- \\
8,0\end{array}$ \\
\hline $\mathrm{C} 12: 0$ & Láurico & $\begin{array}{l}50,49^{\mathrm{a}} \\
\pm \\
1,31\end{array}$ & $\begin{array}{l}50,37^{\mathrm{a}} \\
\pm \\
1,12\end{array}$ & $\begin{array}{l}50,80^{\mathrm{a}} \\
\quad \pm \\
1,47\end{array}$ & $\begin{array}{c}43,0- \\
51,0\end{array}$ \\
\hline C14:0 & Mirístico & $\begin{array}{l}20,81^{\mathrm{a}} \\
\pm \\
1,02\end{array}$ & $\begin{array}{c}20,29^{\mathrm{a}} \\
\pm \\
1,46\end{array}$ & $\begin{array}{l}20,10^{\mathrm{a}} \\
\quad \pm \\
1,25\end{array}$ & $\begin{array}{c}16,0- \\
21,0\end{array}$ \\
\hline C16:0 & Palmítico & $\begin{array}{l}9,72^{\mathrm{a}} \\
\pm \\
0,71\end{array}$ & $\begin{array}{l}9,77^{\mathrm{a}} \\
\pm \\
1,03\end{array}$ & $\begin{array}{l}9,36^{\mathrm{a}} \\
\pm \\
0,96\end{array}$ & $\begin{array}{l}7,5- \\
10,0\end{array}$ \\
\hline C18:0 & Esteárico & $\begin{array}{l}3,43^{\mathrm{a}} \\
\pm \\
0,22\end{array}$ & $\begin{array}{l}3,45^{\mathrm{a}} \\
\quad \pm \\
0,43\end{array}$ & $\begin{array}{l}3,31^{\mathrm{a}} \\
\pm \\
0,39\end{array}$ & $\begin{array}{c}2,0- \\
4,0\end{array}$ \\
\hline $\mathrm{C} 18: 1 c$ & Oléico & $\begin{array}{l}5,91^{\mathrm{a}} \\
\quad \pm \\
0,39\end{array}$ & $\begin{array}{l}5,84^{\mathrm{a}} \\
\pm \\
0,43\end{array}$ & $\begin{array}{l}5,67^{\mathrm{a}} \\
\pm \\
0,66\end{array}$ & $\begin{array}{l}5,0- \\
10,0\end{array}$ \\
\hline $\mathrm{C} 18: 2 c$ & Linoléico & $\begin{array}{l}0,87^{\mathrm{a}} \\
\pm \\
0,10\end{array}$ & $\begin{array}{l}0,83^{\mathrm{a}} \\
\quad \pm \\
0,06\end{array}$ & $\begin{array}{l}0,89^{\mathrm{a}} \\
\pm \\
0,89\end{array}$ & $\begin{array}{c}1,0- \\
2,5\end{array}$ \\
\hline Picos nã & o identificados & 0,19 & 0,11 & 0,49 & - \\
\hline
\end{tabular}

a Médias na mesma linha seguidas de letras diferentes indicam diferença estatística.

Os ácidos graxos saturados foram predominantes, sendo representativamente superiores aos ácidos graxos monoinsaturados e polinsaturados, corroborando com os dados encontrados na literatura. $\mathrm{O}$ ácido láurico foi principal ácido graxo presente no óleo de coco (cerca de $50 \%$ do total) e o processo de aquecimento foi incapaz de alterar significativamente suas concentrações.

Diferente do observado para o perfil de ácidos graxos, onde não encontramos diferenças entre os grupos, o índice de acidez, assim como o índice de peróxidos foi alterado após submeter o óleo de coco ao aquecimento (Tabela 2).
Tabela 2 - Índice de acidez e índice de peróxidos do óleo de coco in natura (OCIN), aquecido até ponto de fumaça (OCAQ) e usado em fritura (OCFR)

\begin{tabular}{lccc}
\hline & OCIN & OCAQ & OCFR \\
& & & \\
$\begin{array}{l}\text { Índice de Acidez } \\
\text { (\% ácido oléico) }\end{array}$ & $0,50^{\mathrm{a}} \pm 0,11$ & $0,90^{\mathrm{b}} \pm 0,19$ & $1,00^{\mathrm{b}} \pm 0,03$ \\
Índice de & & & \\
$\begin{array}{l}\text { Peróxidos } \\
(\mathrm{mEq} / 1000 \mathrm{~g})\end{array}$ & $4,64^{\mathrm{a}} \pm 1,30$ & $11,67^{\mathrm{b}} \pm 1,93$ & $5,12^{\mathrm{a}} \pm 2,00$ \\
\hline
\end{tabular}

a, b Médias na mesma linha seguidas de letras diferentes indicam diferença estatística.

A acidez foi superior nas amostras de OCAQ e OCFR, comparados ao OCIN. Já a formação de peróxidos foi superior no OCAQ, diferindo significativamente das demais amostras.

A presença do MDA foi detectada nas três amostras e as concentrações diferiram significativamente entre cada uma delas, sendo maior no OCAQ, seguido pelo OCFR e, por último no OCIN. Em relação à capacidade antioxidante, observa-se maior atividade no óleo de coco in natura comparado ao óleo aquecido ou utilizado em fritura (Tabela 3).

Tabela 3 - Concentração de MDA e atividade antioxidante no óleo de coco in natura (OCIN), aquecido até ponto de fumaça (OCAQ) e usado em fritura (OCFR).

\begin{tabular}{lccc}
\hline & OCIN & OCAQ & OCFR \\
$\begin{array}{l}\text { Malondialdeído } \\
(\mu \mathrm{mol} / \mathrm{mg})\end{array}$ & $0,16^{\mathrm{a}} \pm 0,01$ & $0,46^{\mathrm{b}} \pm 0,03$ & $0,32^{\mathrm{c}} \pm 0,03$ \\
ARR $(\%)$ & $27,20^{\mathrm{a}} \pm 1,53$ & $19,30^{\mathrm{b}} \pm 0,49$ & $21,9^{\mathrm{b}} \pm 0,49$ \\
& \\
$\begin{array}{l}\text { a, b, c } \text { Médias na mesma linha seguidas de letras diferentes indicam } \\
\text { diferença estatística }\end{array}$
\end{tabular}

\section{Discussão}

O presente estudo evidenciou que processos de aquecimento alteram as características físico-químicas e de oxidação do óleo de coco, sem, contudo, influenciar de forma significativa seu perfil de ácidos graxos. $\mathrm{O}$ aquecimento de óleos e gorduras é um processo complexo que envolve reações de hidrólise, oxidação e polimerização da molécula de triacilglicerol, 
produzindo novas moléculas e compostos voláteis. ${ }^{(18)}$ Essas reações podem levar à redução do teor de ácidos graxos polinsaturados, como os ácidos graxos linoléico e linolênico, comprometendo a qualidade nutricional do óleo, por se tratarem de ácidos graxos essenciais. (19) No nosso estudo, o tratamento térmico aplicado às amostras não foi capaz de alterar as concentrações do ácido linoléico; possivelmente o binômio tempo/ temperatura empregados não tenham sido suficientes para causar essa redução.

A redução dos ácidos graxos polinsaturados é descrita no estudo de Sanibal e Mancini-Filho, ${ }^{(10)}$ onde foram avaliadas as alterações na composição dos ácidos graxos do óleo de soja e da gordura parcialmente hidrogenada utilizados no processo de fritura. Os autores observaram redução na concentração dos ácidos graxos polinsaturados e, por consequência, um aumento proporcional dos ácidos graxos saturados. No caso do óleo de coco, além da influência do tempo/ temperatura empregados, a elevada concentração de ácidos graxos saturados também confere uma maior estabilidade em termos de reações de hidrólise e polimerização.

Observamos a ocorrência de picos não identificados nos cromatogramas. Estes são devidos à formação de compostos diferentes de ácidos graxos. Nas amostras do óleo de coco utilizado na fritura de batatas por imersão, pode ainda ter ocorrido trocas entre o óleo e o alimento, o que justifica a maior concentração de picos não identificados nesse grupo.

A resolução prevê uma acidez máxima, expressa em \% de ácido oléico, de 0,3\% ácido oléico/100g de óleo de coco. ${ }^{(4)}$ A determinação desse índice é um dos principais parâmetros usados para avaliar a qualidade dos óleos e gorduras para consumo. ${ }^{(20)} \mathrm{A}$ decomposição dos óleos, seja por hidrólise, oxidação ou fermentação, é acelerada por luz e calor, com a liberação de ácidos graxos livres (representado pela acidez)..$^{(21)}$ Essa decomposição é significante, principalmente em óleos que possuem grande quantidade de ácidos graxos de baixo peso molecular, como os encontrados no óleo de $\operatorname{coco}^{(22)}$

O índice de acidez foi superior ao recomendado pela legislação nos três grupos. A exposição à luz, o tempo de armazenamento e o contato com oxigênio, podem explicar em partes, a acidez elevada na amostra in natura; contudo, essa foi significativamente inferior às demais amostras. A acidez observada no óleo aquecido até o ponto de fumaça e usado na fritura indica hidrólise dos triglicerídeos, com liberação dos seus constituintes principais, os ácidos graxos em sua forma livre. A acidez será maior quanto maior for a exposição às altas temperaturas.

Para o índice de peróxidos, a ANVISA ${ }^{(4)}$ recomenda que este deva ser de, no máximo, $10 \mathrm{mEq} / \mathrm{kg}$; valores acima indicam redução da qualidade da gordura. Os peróxidos são os primeiros compostos formados quando um óleo ou gordura deteriora (produtos primários da oxidação). ${ }^{(23)}$ Logo, o índice de peróxidos é um método que apresenta maior aplicabilidade se utilizado para avaliar estágios iniciais da deterioração, quando os peróxidos atingem um pico e depois declinam. A partir de então, tem-se o aumento das concentrações dos produtos secundários da oxidação, como o malondialdeído (MDA). ${ }^{(10,24)}$

O índice de peróxidos do OCIN e OCFR não ultrapassou os valores preconizados pela legislação. Já para o óleo de coco aquecido até o ponto de fumaça, o valor foi superior ao recomendado e diferiu significativamente dos demais grupos. Nesse caso, podemos inferir que, a presença do alimento pode retardar a formação desses compostos, devido ao vapor formado a partir da umidade do alimento, uma vez que no óleo utilizado na fritura de batatas, mesmo com o tempo de exposição ao aquecimento sendo maior (4 minutos $x 1$ minuto), a formação de peróxidos foi menor.

Um dos componentes presentes no óleo de coco que podem contribuir para que a formação de peróxidos seja reduzida são os compostos fenólicos (antioxidantes naturais), responsáveis pela inibição do processo oxidativo. Ressalta-se que o óleo de coco industrializado é acrescido do antioxidante sintético butil-hidroxianisol (BHA), sendo este considerado efetivo até mesmo quando o óleo é submetido a temperaturas elevadas. ${ }^{(7)}$

$\mathrm{O}$ estudo realizado por Pinto et al. ${ }^{(22)}$, que avaliou os índices de peróxido e acidez da gordura vegetal hidrogenada e de óleos vegetais como milho e girassol submetidos à fritura, foi possível observar que a gordura vegetal hidrogenada foi a mais estável. Sua composição é semelhante ao óleo de coco no que se refere à elevada concentração de ácidos graxos saturados, conferindo maior estabilidade.

A mensuração dos compostos oxidados formados no aquecimento também pode ser realizada por meio do teste de substâncias reativas ao ácido tiobarbitúrico (TBA), método que fornece informações sobre a extensão da peroxidação lipídica em sistemas in vitro. ${ }^{(25)}$ Esse teste avalia a presença de produtos secundários da oxidação lipídica, como o malondialdeído (MDA), um dialdeído formado durante a oxidação dos ácidos graxos. ${ }^{(26)}$ 
No OCFR a formação de MDA foi significativamente menor quando comparado ao OCAQ, uma vez que a presença do alimento pode retardar o processo oxidativo, e consequentemente a formação desse subproduto. No OCIN também houve a detecção de MDA, possivelmente pela exposição a fatores que levam à oxidação, como o contato com oxigênio, umidade, luz e contaminação por metais de transição. (27) Porém, nesse caso, a formação de MDA foi menos intensa que nos demais grupos.

Em relação à capacidade antioxidante, foi observado que o OCIN apresentou maior capacidade de sequestrar o radical DPPH, comparado aos demais tratamentos. Esse resultado demonstra que o processo de aquecimento do óleo leva ao consumo dos antioxidantes, com o objetivo de inibir a formação dos produtos da oxidação. ${ }^{(28)}$

O consumo de alimentos preparados em óleos ou gorduras processados, contendo produtos oxidados pode trazer prejuízos à saúde. Esses produtos podem provocar ligações cruzadas nas lipoproteínas de baixa densidade, causando acúmulo de colesterol nos vasos sanguíneos. Além disso, os radicais livres formados no processo de oxidação reagem com os lipídeos presentes nas membranas celulares, causando lesões ou mesmo sua destruição. O DNA e o RNA também podem ser afetados, mudando a função celular e levando ao desenvolvimento de doenças como câncer, aterosclerose, artrite e envelhecimento precoce. ${ }^{(29,30)}$

Animais alimentados com dietas ricas em óleos e gorduras exaustivamente processados, apresentam alterações metabólicas importantes, resultando em perda de peso, supressão do crescimento, diminuição do tamanho do fígado e rins, má absorção de gorduras, diminuição das taxas de dessaturação dos ácidos graxos linoléico e linolênico. ${ }^{(31)}$

Os compostos polares, como a acroleína, formados com a oxidação lipídica provocam irritação do trato gastrintestinal, diarreia, redução do crescimento e, em alguns casos, até morte em animais. ${ }^{(32)}$ Com o aumento dos compostos poliméricos, foi demonstrada uma possível inibição ou pelo menos retardo na ação da lipase pancreática na hidrólise de triglicerídeos não oxidados, tornando a digestibilidade diminuída. ${ }^{(33)}$

O padrão de qualidade e identidade de óleos e gorduras é definido por algumas características físicoquímicas, como índice de iodo, índice de peróxidos e índice de acidez, além do próprio perfil de ácidos graxos, sendo que os índices de acidez e peróxidos são os únicos parâmetros químicos escolhidos pela norma brasileira para regulamentar a adequação para o consumo no país. Contudo, no Brasil, ainda não existe legislação específica para óleos ou gorduras submetidos a tratamentos térmicos, como no caso das frituras ${ }^{(34-36)}$

Concluímos que os tratamentos térmicos aos quais o óleo de coco foi submetido foram capazes de alterar suas características físico-químicas e oxidativas. Porém, tais alterações não foram suficientes para modificar o perfil de ácidos graxos da mesma. Considerando os possíveis malefícios associados ao consumo de óleos e gorduras degradados, desencorajamos a utilização do óleo de coco submetido a tratamentos térmicos. Enfatizamos a importância da criação de metodologias específicas para avaliação da qualidade de óleos e gorduras submetidas ao aquecimento, por possibilitar melhor controle dos aspectos nutricionais e sensoriais dos óleos/gorduras destinados ao consumo.

\section{Referências}

1 Mansor TST, Che Man YB, Shuhaimi M, Abdul Afiq MJ, Ku Nurul FKM. Physicochemical properties of virgin coconut oil extracted from different processing methods. Int Food Res J. 2012;19(3):837-45.

2 Angelis RCD. Novos conceitos em nutrição: reflexões a respeito do elo dieta e saúde. Arq Gastr. 2001 Oct-Dec; 38(4):269-71.

3 Myhrstad MCW, Narverud I, Telle-Hansen VH, Karhu T, Lund DB, Herzig KH et al. Effect of the fat composition of a single high-fat meal on inflammatory markers in healthy Young women. $\mathrm{Br}$ J Nutr. 2011 Dec;106(12);1826-35. doi: 10.1017/ S0007114511002510.18261835.

4 Agência Nacional de Vigilância Sanitária (BR). Resolução $n^{0}$ 482, de 23 de setembro de 1999. Regulamento Técnico para Fixação de Identidade e Qualidade de óleos e gorduras vegetais. [Internet]. 1999 [citado 2016 dez 4]. Disponível em: http:// www.anvisa.gov.br/legis/resol/482_99.htm.

5 Debmandal M, Mandal S. Coconut (Cocos nucifera L.: Arecaceae): in health promotion and disease prevention. Asian Pac J Trop Med. 2011 Mar;4(3):241-7. doi: 10.1016/S1995 7645(11)60078-3. 
6 Silva RSM, Fortes RC, Soares HF. Efeitos da suplementação dietética com o óleo de coco no perfil lipídico e cardiovascular de indivíduos hipercolesterolêmicos. Brasília Méd. 2011 June; 48(1).

7 Seneviratne KN, Hapuarachchi CD, Ekanayake S. Comparison of the phenolic-dependent antioxidant properties of coconut oil extracted under cold and hot conditions. Food Chem. 2009 June;114:1444-9. doi: https://doi.org/10.1016/j. foodchem.2008.11.038.

8 Bhatnagar AS, Prasanth Kumar PK, Hemavathy J, Gopala Krishna AG. Fatty acid composition, oxidative stability, and radical scavenging activity of vegetable oil blends with coconut oil. J Am Oil Chem Soc. 2009 Oct;86(10):991-9.

9 Sabarense CM, Mancini-Filho J. Efeito da gordura vegetal parcialmente hidrogenada sobre a incorporação de ácidos graxos trans em tecidos de ratos. Rev Nut. 2003 Oct-Dec;16(4):22-38. doi: $\quad$ http://dx.doi.org/10.1590/S141552732003000400003

10 Sanibal EAA, Mancini-Filho J. Alterações físicas, químicas e nutricionais de óleos submetidos ao processo de fritura. Cad Tecnol Alim. Bebidas. 2002;18(64).

11 Marques AC, Valente TB, Rosa CS. Formação de toxinas durante o processamento de alimentos e as possíveis conseqüências para o organismo humano. Rev. Nutr. 2009 Mar-Apr;22(2):283-93. doi: 10.1590/S1415-52732009000200010.

12 Moigradean D, Poiana MA, Gogoasa I. Quality characteristics and oxidative stability of coconut oil during storage. J Agroalimentary Proc Technolog. 2012;18(4):272-6.

13 Seneviratne KN, Sudarshana Dissanayake DM. Variation of phenolic content in coconut oil extracted by two conventional methods. J Agroalimentary Proc Technolog. 2008;43(4):597602.

14 Hartman L, Lago RCA. Rapid preparation of fatty acid methyl esters from lipids. Lab Pract. 1976 July; 22: 475-7.
15 Association of Official Analytical Chemists. Official methods of analysis of the association of official analytical chemists. Washington: AOAC; 1990.

16 Silva FAM, Borges MFM, Ferreira MA. Métodos para avaliação do grau de oxidação lipídica e da capacidade antioxidante. Quím. Nova 1999 janfev;22(1):94-103.

17 Brand-Williams W, Cuvelier ME, Berset C. Use of a free radical method to evaluate antioxidant activity. Lebensm. wiss. technol. 1995;28(1):25-30. doi: https://doi.org/10.1016/S0023-6438(95)80008-5

18 Aladedunye FA, Przybylski R. Degradation and nutritional quality changes of oil during frying. Jaocs. 2009 Feb;86(2):149-56. doi: 10.1007/ s11746-008-1328-5, 2009.

19 Corsini MS, Jorge N. Estabilidade oxidativa de óleos vegetais utilizados em frituras de mandioca palito congelada. Ciênc Tecnol Aliment. 2006 jan-mar;26(1):27-32. doi: 10.1590/S010120612006000100005.

20 Malacrida CR, Jorge N. Alterações do óleo de soja em frituras: efeitos da relação superfície/ volume e do tempo de fritura. Hig Aliment. 2005 mar;19(129):25-31.

21 Zenebon O, Pascuet NS, Tiglea P. Métodos físicoquímicos para análise de alimentos. São Paulo: Instituto Adolfo Lutz; 2008.

22 Pinto EP, Borges CD, Teixeira AM, Zambiazi RC. Características da batata frita em óleos com diferentes graus de insaturação. B Ceppa. 2003 juldez;21(2):293-302. doi: http://dx.doi.org/10.5380/ cep.v21i2.1166

23 Liau KM, Lee YY, Chen CK, Rasool AHG. An Open-Label Pilot Study to Assess the Efficacy and Safety of Virgin Coconut Oil in Reducing Visceral Adiposity. ISRN Pharmacol. 2011;1-7. doi: org/10.5402/2011/949686.

24 Mendonça MA. Alterações químicas, físicas e nutricionais em óleos submetidos ao processo de fritura [monografia]. Brasília (DF): Universidade de Brasília; 2006. 
25 Jorge N, Lopes MRV. Avaliação de óleos e gorduras de frituras coletados no comércio de São José do Rio Preto-SP. Aliment Nutr. 2003;14(2):149-56.

26 Lima ES, Abdalla DSP. Peroxidação lipídica: mecanismos e avaliação em amostras biológicas. Rev Bras Cienc Farm. 2001 set-dez;37(3):293-303.

27 Ramalho VC, Jorge N. Antioxidants used in oils, fats and fatty foods. Quím Nova. 2006 July-Aug; 29(4): 755-60. doi: 10.1590/S0100-40422006000400023.

28 Janu C, Soban Kumar DR, Reshma MV, Jayamurthy P, Sundaresan A, Nisha P. Comparative study on the total phenolic content and radical scavenging activity of common edible vegetable oils. J Food Biochem. 2014 Feb;38(1):38-49. dói: 10.1111/ jfbc. 12023.

29 Rique ABR, Soares EA, Meirelles CM. Nutrition and exercise on cardiovascular disease prevention and control. Rev Bras Med Esporte. 2002 Nov-Dec; 8(6). doi: 10.1590/S1517-86922002000600006.

30 Araújo JMA. Química de alimentos: teoria e prática. Viçosa: UFV; 2004.

31 Mendonça MA, Borgo LA, Araújo WMC, Novaes MRCG. Alterações físico-químicas em óleos de soja submetidos ao processo de fritura em unidades de produção de refeição no Distrito Federal. Comun Ciênc Saúde. 2008 abr-jun;19(2):115-22.

32 Corsini MS, Jorge N, Miguel AMRO, Vicente E. Perfil de ácidos graxos e avaliação da alteração em óleos de fritura. Quím Nova. 2008;31(5): 956-61. doi: 10.1590/S0100-40422008000500003.

33 Marques AC, Valente TB, Rosa CS. Formação de toxinas durante o processamento de alimentos e as possíveis conseqüências para o organismo humano. Rev Nutr. 2009 mar-abr;22(2):283-93. doi: 10.1590/S1415-52732009000200010.

34 Gregório BM, Andrade ECB. Influência do aquecimento sobre as propriedades físicoquímicas de óleos comestíveis. Hig Alimentar. 2004;18(124):78-84.

35 Carvalho SM, Ogliari PJ, Barrera-Arellano D, Block JM. Efeito da adição de tocoferóis naturais sobre a qualidade de óleo de soja refinado e embalado em PET durante a estocagem. Braz J Food Technol. 2008 Apr-June;11(2):134-43.
36 Freire PCM, Mancini-Filho J, Ferreira TAPC. Principais alterações físico-químicas em óleos e gorduras submetidos ao processo de fritura por imersão: regulamentação e efeitos na saúde. Rev Nutr. 2013 mio-jun; 26(3):353-358. doi: http:// dx.doi.org/10.1590/S1415-52732013000300010.
Recebido em: 16 jun. 2017 Aceito em: 18 jan. 2018 